\title{
Corpus
}

Archivos virtuales de la alteridad americana

Vol. 8, No 2 | 2018

Julio / Diciembre 2018

\section{Métodos políticos}

\section{Florencia Malbran}

\section{OpenEdition}

\section{Journals}

Electronic version

URL: http://journals.openedition.org/corpusarchivos/2723

DOI: $10.4000 /$ corpusarchivos. 2723

ISSN: 1853-8037

\section{Publisher}

Diego Escolar

\section{Electronic reference}

Florencia Malbran, « Métodos políticos », Corpus [En línea], Vol. 8, No 2 | 2018, Publicado el 25 diciembre 2018, consultado el 22 abril 2019. URL : http://journals.openedition.org/ corpusarchivos/2723; DOI : 10.4000/corpusarchivos.2723

This text was automatically generated on 22 April 2019

Licencia Creative Commons: Atribución-NoComercial 2.5 Argentina (CC BY-NC 2.5 AR) 


\title{
Métodos políticos
}

\author{
Florencia Malbran
}

1 La era del Antropoceno, marcada por una honda mutación ecológica, nos exige pensar lo viviente junto a la caída de la división cultura-naturaleza, o yo interior-realidad exterior. Cabe preguntarse, entonces, qué desafíos metodológicos presenta el abordaje a estos conceptos en cuya reformulación está implicada la mismísima idea de "mundo". Sin embargo, esta pregunta hermenéutica es más que un interrogante sobre metodología, ante todo, es un interrogante político: entraña la posibilidad de observar el mundo de otra manera y por ello involucra también la posibilidad de que el mundo evolucione de otro modo, modificando su estado actual, caracterizado por la destrucción sistemática del medio ambiente, el patriarcado, el ascenso de los extremismos y la vulneración de los derechos humanos en amplios sectores de la población global (lo evidencian movimientos como Black Lives Matter y Ni Una Menos, o la alarmante crisis de inmigrantes en Europa y los Estados Unidos).

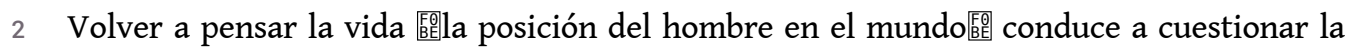
"razón". La Ilustración hizo prevalecer a la razón en tanto facultad del hombre para acceder al mundo, comprenderlo y progresar en (y sobre) él. Sostenidos en esta prevalencia, los hombres sometieron el planeta a inmensos cambios, organizados en modos de actuación que alteraron el clima, el paisaje y la vida animal, comprometiendo asimismo a la propia existencia humana.

3 La crítica a la razón, no obstante, no puede opacar nuestra implicación en el pensamiento ilustrado. Estamos enmallados en la Ilustración: sujetos en la red de sus ideas, atrapados en algunos de sus valores. El estado de derecho, la abolición de la tortura y la inviolabilidad del cuerpo son bastiones que se deben, en gran medida, al Siglo de las Luces. Jay Bernstein recuerda el siglo XVIII y advierte "un momento moral extraordinario durante el cual la subjetividad ilustrada y la modernidad política ilustrada emergieron juntas a través de la abolición de la tortura. Si al estado no se le permite ya torturar a los acusados (arrancar a los individuos información o una confesión), si los individuos deben presumirse inocentes hasta que se pruebe su culpabilidad, y si el estado no se arroga ya el derecho de violentar físicamente a los convictos, se instituye una nueva relación entre el 
estado y el individuo, dotando también de un nuevo sentido al cuerpo humano. Al estado se le prohíbe ahora 'tocar' el cuerpo de sus ciudadanos” (Bernstein 2018, pp. 208-209).

Esta libertad y la integridad corporal son, sin dudas, derechos fundamentales de las personas. La libertad se encuentra en la factura del pensamiento-filosófico y políticooccidental. "Para esta Ilustración no se requiere más que una cosa, libertad", aseveró Kant (Kant 1978, p. 28). ${ }^{1}$ Es en virtud de esta negativa a la opresión que es difícil abandonar de plano, sin reservas, en la crítica a la razón, los bastiones ilustrados. Lo manifiestan así las palabras descarnadas de Michelle M. Wright cuando escribe:

"La Ilustración es el olor nauseabundo que crean las intenciones aparentemente buenas, mezcladas con una estupidez decrépita y una autoestima completamente podrida; un olor que me resulta difícil no olfatear, de la misma forma en que sigo revisando si mi leche de almendras (la última moda para la salud... ¡traída también por la Ilustración!) se puso mala. Y la Ilustración es lo que me define, tan frecuentemente, en tantos momentos. Es el pedestal en el cual me paro siempre estirándome para alcanzar a ver, más allá, alguna alternativa factible" (Wright 2018, p. 204).

5 La crítica a la idea de progreso, la determinación racional y el dominio es muy necesaria, tan necesaria como el reconocimiento de nuestra implicación con el pensamiento ilustrado.

El poder de la crítica radica en desmarcarnos, proveernos de algún tipo de diferenciación en relación con la Ilustración, sin negarla absolutamente. ¿Qué otros métodos para organizar el saber podrían servirnos? La edición de la Bienal del San Pablo titulada “ Incerteza Viva", realizada en 2016 bajo la curaduría general de Jochen Volz, sugería modos alternativos para ver el mundo.

7 Las obras en exhibición daban cuenta del caos y la desazón actual, mostrando la apertura de un tiempo distinto al que el planeta vivió hasta ahora. Según Volz: "El arte jugó siempre con lo desconocido. Históricamente, el arte insistió en un vocabulario que permite la ficción y jerarquiza la incertidumbre. La información se pierde y la duda persiste, pero el arte puede modificar estas paradojas mediante sus operaciones por fuera de los sistemas, escalas y paradigmas establecidos, introduciendo patrones alternativos" (Volz 2016, p. 23). De este modo, el arte podría llamarnos al trabajo persistente de abrir otros lugares desde los cuales operar.

Es posible proponer que en la bienal se exponía arte proveniente de diversas culturas que, al concentrase en América Latina, invitaba a contemplar el pasado y el futuro desde el "entrelugar" regional. Aquí el potencial político de "Incerteza Viva": formular, a través del arte contemporáneo incluido en una bienal latinoamericana, la invitación a encontrar intersticios, pliegues, en las derivas del pensamiento ilustrado. Recordemos que a partir de la lectura regional de ciertos problemas europeos se produce un "entrelugar", esto es, "la noción de unidad sufre un giro, es contaminada a favor de una mezcla sutil y compleja entre el elemento europeo y el elemento autóctono: una especie de infiltración progresiva efectuada por el pensamiento salvaje, o sea, apertura del único camino posible que podría llevar a la descolonización". ${ }^{2}$ Las obras de arte, europeas y no europeas, exhibidas en la bienal advertían que no hay una simple opocición, un antónimo, al pensamiento ilustrado. Más bien, estas obras auspiciaban una perspectiva de reposicionamientos, desplazamientos y puntos de fuga argumentales.

El artista francés Pierre Huygue presentó en la bienal dos obras interrelacionadas tituladas Des-Extinção (2016) y Des-Extinção (S.P. Evolução) (2016). La primera era una 
enorme proyección en un espacio oscuro. Huygue había filmado el interior de una gema de ámbar. Conviene reparar en que el ámbar posee un origen orgánico; se formó, durante la prehistoria, a partir de la resina de ciertos árboles. El tronco de esos árboles segregó una sustancia liquida que se endureció y se transformó en ámbar, hace sesenta y seis millones de años, y por ello muchas gemas de ámbar contienen fósiles de insectos. Los seres vivos que rodeaban la corteza de los árboles, hoy extinguidos, quedaron petrificados en las gemas, en tan buen estado de preservación que es factible estudiar sus secuencias de ADN. Huyghe, valiéndose de lentes especiales, logró un close-up extremo al ámbar. La pantalla brillaba con colores pardos y amarillos dorados. La secuencia en el interior de la gema era lenta. Entre filamentos y vetas translúcidas aparecían los insectos, inmóviles, casi perfectos. Belleza y entomología se fundían en una experiencia preciosa. La cámara de Huygue hacía foco en una pareja de insectos copulando. Des-Extinção reproducía especies extinguidas. Pero la vuelta a la vida no era sólo fílmica. En una pequeña sala contigua, Huygue exponía Des-Extinção (S.P. Evolução). La luz era fuerte y había un amplio ventanal que abría al Parque Ibirapuera. Pululaban allí insectos reales. Eran moscas

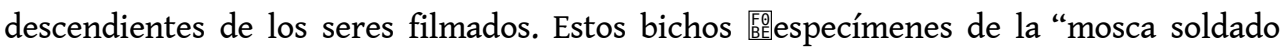
negra" o "Hermetia illucens"酒 habían sido criados en un laboratorio, en colaboración con el Instituto Biológico de San Pablo.

A través de ambas obras, Huyghe subrayaba la habilidad de adaptación de los organismos. Hacía ajustes para revertir extinciones. Como ya lo había realizado en trabajos anteriores, Huyghe ponía en jaque las oposiciones naturaleza-cultura y biología-tecnología. "Miro cómo cambian las cosas, se transforman, se metabolizan [...] Intento encontrar una palabra para decir: algo está vivo", había señalado el artista (Huygue 2013, p. 55). DesExtinção y Des-Extinção (S.P. Evolução) proponían una relectura de la vida, sus momentos, su evolución. Las obras de Huyghe reactivaban el poder del arte para animar la reflexión sobre preguntas tan medulares como urgentes: ¿Qué existe? ¿Cómo concebir la vida? 


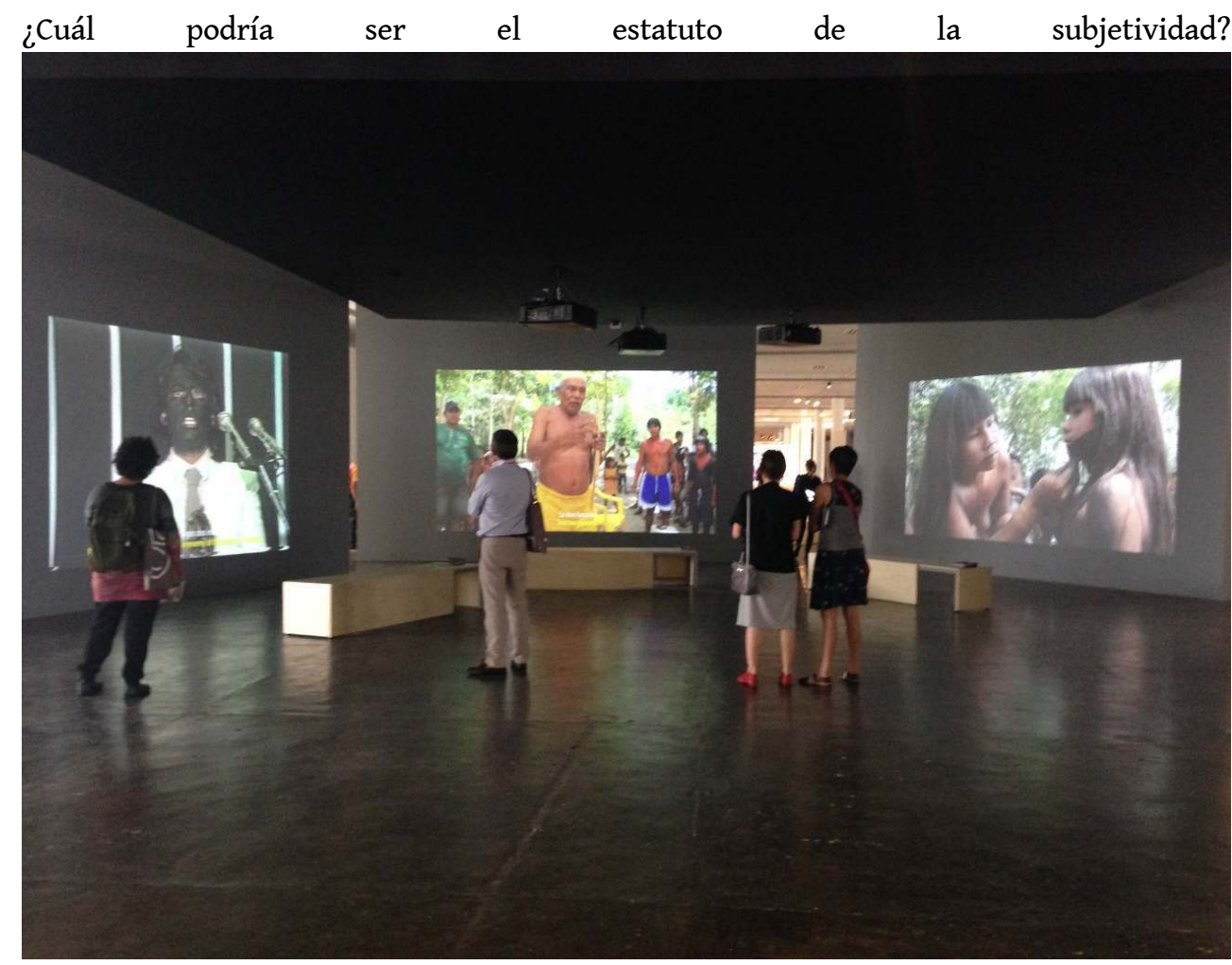

Figura 1.Vídeo nas Aldeias, O Brasil dos índios: um arquivo aberto (2016). Vista de instalación, Bienal de San Pablo. Fotografía: Vincent Carelli

10 La organización brasileña Vídeo nas Aldeias (VNA) creó, especialmente para la bienal, la instalación $O$ Brasil dos índios: um arquivo aberto (2016). Tres grandes pantallas creaban un espacio poligonal que envolvía a los espectadores. Se veían allí dentro ochenta y un fragmentos de video, reunidos a partir del material audiovisual coleccionado durante los treinta años que esta organización sin fines de lucro ha estado en funcionamiento.

11 Vídeo nas Aldeias, fundada por el antropólogo y documentalista Vincent Carelli, aspira otorgar visibilidad a los indígenas brasileños mediante la producción de películas. Los filmes y videos están realizados por los propios indígenas, para prevenir la mirada externa de los ojos imperiales que narran al "otro" como inferior, exótico o primitivo. Además, Vídeo nas Aldeias no sólo estimula la producción de directores indígenas, también circula sus obras, dentro y fuera de sus comunidades de origen.

12 Al ingresar en 0 Brasil dos índios: um arquivo aberto, los espectadores se encontraban rodeados de relatos de mitos, rituales, demostraciones políticas y situaciones de contacto con los blancos, narradas por integrantes de pueblos indígenas como los Guarani Kaiowá, Gavião, Kayapó, Krahô, Maxakali y Yanomami. La instalación afirmaba la presencia y la potencia indígena. De acuerdo con Volz:

13 "Estos fragmentos, unidos por el poder de sus imágenes y discursos, constituyen una instancia más de resistencia colectiva contra los intentos de borrar a los pueblos indígenas, volviéndolos invisibles, y provocan una amplia reflexión sobre la alteridad y las convenciones de las perspectivas culturales" (Volz 2016, s/p).

o Brasil dos índios se completaba como un "campo sonoro". Los espectadores podían escuchar en un sector de la exposición, utilizando auriculares, tanto una selección de 
cantos ceremoniales Mbya Guarani, Guarani Kaiowá y Ñandeva, como canciones indígenas tomadas de películas auspiciadas por Vídeo nas Aldeias.

La intervención de Vídeo nas Aldeias en la bienal no sólo mostraba de qué maneras los indígenas enfrentan la negación de sus identidades en espacios neocoloniales, sino que, además, expresaba que el reconocimiento sólido de sus creaciones -su estética, sus conceptos y también su epistemología- puede conducirnos a la reconfiguración de

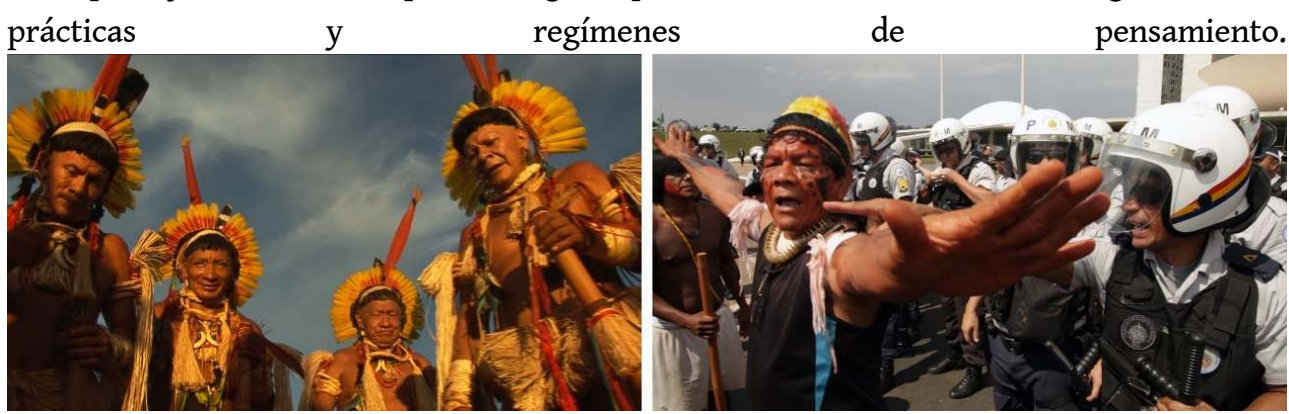

Figura 2. Vídeo nas Aldeias, O Brasil dos índios: um arquivo aberto (2016). Detalle.

Analizadas en tándem, las obras de Huyghe y de Vídeo nas Aldeias podrían facilitar una metodología para volver a pensar el mundo. La yuxtaposición de estas obras, expuestas incluso en el mismo piso del gran Pavilhão Ciccillo Matarazzo, donde se presenta la bienal, ofrecía una experiencia que generaba la sensación de incertidumbre. ${ }^{3} \mathrm{El}$ título de la bienal, "Incerteza Viva", adelantaba ya el cuestionamiento de la certeza o la ausencia de conocimientos seguros y claros sobre la realidad actual. Las obras de Huyghe acompañadas por la instalación de Vídeo nas Aldeias ratificaban la incertidumbre. Juntas, estas obras sugerían que existen varios fundamentos y métodos de conocimiento, y que no son excluyentes. La exhibición en un mismo espacio de obras como Des-Extinção, DesExtinção (S.P. Evolução) y O Brasil dos índios: um arquivo aberto invitaba a la elaboración de nuevas preguntas sobre la naturaleza y la cultura, el ser y el otro, lo humano y la tecnología.

La bienal afirmaba que de la confrontación entre el pensamiento eurocéntrico y el latinoamericano emergía una nueva hibridez que podría responder a la redefinición de los lugares de la humanidad y la especie. En efecto, la contemplación de las prácticas estéticas expuestas en San Pablo invitaba al ensayo de comparaciones y fusiones entre las herramientas metodológicas que ofrece el pensamiento occidental y perspectivas que provienen de otro tipo de consciencias históricas, como las del pensamiento amerindio. Esta mirada híbrida a la razón antropocéntrica produce preguntas importantes. ¿Se acoplan, por ejemplo, la teoría del perspectivismo de Eduardo Viveiros de Castro y el principio de individuación de Gilbert Simondon? ¿Qué imagen del devenir y los centros de consciencia, o de lo viviente, nos devolverían juntas? ¿Qué ocurre si se ubican frente a frente las trayectorias intelectuales de Davi Kopenawa y Bruno Latour? La creatividad del arte pone de relieve también la creatividad del pensamiento, esto es, la posibilidad de anticipar un futuro sin bloquear totalmente el pasado, más bien, desplazando episodios del pretérito, aún si sólo son breves flashes. Como lo demostraba "Incerteza Viva", mediante digresiones, combinaciones y oposiciones, podríamos encontrar la capacidad para formular nuevos métodos de conocimiento y actuación sobre lo viviente, para resistir el destino mundial, e incluso atisbar cambiarlo. 


\section{BIBLIOGRAPHY}

Albert, B., Kopenawa, D. (2013). The Falling Sky. Cambridge: Harvard University Press.

Bernstein, J. M. (2018). The New Savagery. Artforum, Summer, 208-209.

Danowski, D., Viveiros de Castro, E. (2015). Há mundo por vir? Ensaio sobre os medos e os fins.

Florianópolis: Desterro - Cultura e Barbárie.

Huygue, P. (2013). Feature. Artist Interview. The Art Newspaper, September, 55.

Kant, E. (1978). Filosofía de la Historia. México: Fondo de Cultura Económica.

Latour, B. (2017). Facing Gaia. Eight Lectures on the New Climatic Regime. Maden, MA: Polity.

Santiago, S. (2000). El entrelugar del discurso latinoamericano. En A. Amante y F. Garramuño (Eds.), Absurdo Brasil. Polémicas en la cultura brasileña. (pp. 61-77.) Buenos Aires: Biblos.

Simondon, G. (2017). On the Mode of Existence of Technical Objects. Minneapolis: Univocal Publishing. Volz, J. (2016). Incerteza viva: 32 Bienal de São Paulo. São Paulo: Fundação Bienal de São Paulo.

Ward, M (1996). What's important about the history of modern art exhibitions? 451-464. En R. Greenberg, B. Ferguson y S. Nairne (Eds), Thinking about Exhibitions. London and New York: Routledge.

Wright, M. M. (2018). Let Us Not Praise Famous Men. Artforum, Summer, 202-205.

\section{NOTES}

1. Kant, en su estudio "Qué es la Ilustración", aseveró que "el uso público de su razón le debe estar permitido a todo el mundo y esto es lo único que puede traer Ilustración a los hombres". Sus argumentos se orientaron en favor de la liberación de la opresión impuestas por el "oficial", el "funcionario de Hacienda" y el "reverendo" (Kant 1978, p. 28).

2. Silviano Santiago desarrolló la noción de "entrelugar" en ensayo clásico sobre la posición excéntrica de América Latina. Según Santiago: “Estos códigos [europeos] pierden su estatuto de pureza y poco a poco se dejan enriquecer por nuevas adquisiciones, por pequeñas metamorfosis, por extrañas corrupciones, que transforman la integridad del Libro Santo y del Diccionario y de la Gramática europeos. El elemento híbrido reina" (Santiago 2000, p. 67).

3. Preguntarse acerca del tipo de experiencias que ofrece una exhibición de arte es clave para comprender el fenómeno de las exposiciones y los saberes que generan. Desde ya, las exposiciones son el vehículo fundamental mediante el cual los espectadores se encuentran con el arte; por lo tanto, las estrategias curatoriales ganan enorme peso al considerar la creación de interpretaciones estéticas y políticas. Cuando reflexionó sobre el sentido de las exposiciones, Martha Ward afirmó que "reviste importancia crítica la realización de un análisis de los espacios y montajes, y de las experiencias 臨tanto sociales como fenomenológicas喟 que las exposiciones preparan para el visitante. Importa preguntarse cómo el armado físico y los métodos de presentación buscan convertir a los visitantes en buenos espectadores y si las exposiciones podrían crear, a través de estos recursos, espectadores a su imagen" (Ward 1996, p. 460). 


\section{AUTHOR}

\section{FLORENCIA MALBRAN}

New York University, Buenos Aires - fmm234@nyu.edu 